Brit. F. industr. Med., 1968, 25, 214.

\title{
A Method for Determination of Trichloroethanol and Trichloroacetic Acid in Urine
}

\author{
SHIRO TANAKA and MASAYUKI IKEDA \\ From the Department of Public Health, Faculty of Medicine, Kyoto University, Kyoto, fapan
}

\begin{abstract}
When trichloroacetic acid (TCA) and trichloroethanol (TCE) in the urine of human subjects, rabbits, rats, and guinea-pigs were determined by Seto and Schultze's (I956) method, the recovery of TCE, added to urine, varied widely from $81.3 \%$ in guinea-pig urine to $16.2 \%$ in rat urine. To obtain the maximum recovery of added TCE, Seto and Schultze's method was further modified to give satisfactory results (recovery rate of 95.9 to $98.5 \%$ ) when applied to human urine as well as to the urine of the above species of animals. Urine samples from human subjects as well as from rats exposed to trichloroethylene were analysed by this modified method. The results showed that the ratio of TCE to TCA varies as a function of environmental trichloroethylene concentration, indicating that the determination of total trichlorocompounds gives a better index of trichloroethylene exposure than does the determination of TCA alone.
\end{abstract}

Trichloroethylene has been used extensively in industry as a degreasing agent and, to some extent, in medicine as an anaesthetic. Its general, pharmacological, and toxicological characteristics were reviewed by Defalque (196I) and Smith (1966). The metabolism of trichloroethylene has been elucidated by Butler (1949), Leibman (1965), Byington and Leibman (1965), Cooper and Friedman (1958), and Friedman and Cooper (1960).

Seto and Schultze (1956) reviewed the methods for the determination of trichloroethylene and its metabolites in biological samples and developed their method for the determination of trichloroethylene, trichloroacetic acid (TCA), and trichloroethanol (TCE) in bovine urine. In this and other methods the glucuronide of TCE in urine is hydrolysed and oxidized by oxidants to TCA, which is determined colorimetrically by the Fujiwara reaction.

When we applied their method to the determination of TCE in the urine of human subjects, rabbits, guinea-pigs, and rats, the recoveries of added TCE were not so good as those reported in bovine urine. This paper presents the results of our experiments to evaluate and modify Seto and Schultze's (1956) method. Good recoveries of added TCE could be achieved when more drastic oxidation conditions were used. The modified method was used to estimate the TCA and TCE in

Received for publication January 29, 1968. the urine of human subjects and of rats exposed to trichloroethylene.

\section{Materials and Methods}

Apparatus, Reagents, and Materials Test tube $(2 \mathrm{~cm} . \times 20 \mathrm{~cm}$.) with an air condenser (cork fitted with a glass tube of $3 \mathrm{~mm}$. inner diameter, and $10 \mathrm{~cm}$. long).

Oxidizing agent: $8 \mathrm{~g}$. of chromium trioxide $\left(\mathrm{CrO}_{3}\right)$, $5 \mathrm{ml}$. of $\mathrm{H}_{2} \mathrm{O}$, and $\mathrm{I} 5 \mathrm{ml}$. of concentrated (about $6 \mathrm{I} \%$ ) $\mathrm{HNO}_{3}$.

Trichloroacetic acid: reagent grade, molarity determined by titration (Pharmacopoeia of the U.S.A., I960).

Trichloroethanol (commercial preparation bought from $\mathrm{K} \& \mathrm{~K}$ Laboratories, Inc., Plainview, N.Y., U.S.A.) was redistilled and the clear fraction obtained at $15 \mathrm{I}^{\circ} \mathrm{C}$. (Merck Index, 1952) was used. The purity was assayed as described later and was found to be $86.0 \pm 0.5 \%$ pure (based on 24 determinations).

Urine samples: normal human urine samples were collected from healthy adults who were on an ordinary Japanese diet and had had no known exposure to trichloroethylene for at least one month prior to the sampling. Urine samples of trichloroethylene-exposed workers were collected on Friday afternoon. Albino rabbits, Hartley guinea-pigs, and Wistar rats were kept on commercial laboratory diet and water ad libitum. The urine of animals was collected separately from faeces.

Determination of Total Trichloro-compounds in Urine after Oxidation to TCA To a test tube with air condenser urine $(0.5 \mathrm{ml}$, diluted if necessary) 
and $0.5 \mathrm{ml}$. of oxidizing agent were added, and the mixture was held at $65^{\circ} \mathrm{C}$. for 4 hours. The tube was cooled in ice, and $2.5 \mathrm{ml}$. of $7.8 \mathrm{~N} \mathrm{KOH}$ were added, followed by $5 \mathrm{ml}$. of pyridine and $0.5 \mathrm{ml}$. of toluene. The mixture was well shaken. Again with the air condenser the tube was held at $65^{\circ} \mathrm{C}$. for 50 minutes for colour development, and cooled in ice. Three $\mathrm{ml}$. of the pyridine layer was mixed thoroughly with $0.6 \mathrm{ml}$. of water and transferred to a cuvette for determination of the extinction at $530 \mathrm{~m} \mu$ (Shimadzu DU Spectrophotometer, Type QR-50). The measurement was carried out within 20 minutes.

Determination of Trichloroacetic Acid in Urine The procedure was identical with the above except that the digestion step was omitted. To the urine $7.8 \mathrm{~N} \mathrm{KOH}$ was added first, then the oxidizing agent was added while the test tube was kept in ice. This prevented oxidation of trichloro-compounds to TCA.

Determination of Trichloroethanol in Urine The above two procedures for total trichloro-compounds and for TCA were conducted on the same urine sample and the difference between the two results was considered to estimate the TCE content.

\section{Results}

Optimum Conditions for Digestion of Urine Sample for Determination of Total Trichlorocompounds To obtain sufficient oxidation of TCE in the urine, it was found that the oxidizing agent and conditions should be more drastic than those used by Seto and Schultze (1956). By their method, the worst recoveries were from rat urine (Table I), which was therefore used to develop a satisfactory method.

Figures $I$ and 2 show that the best results were obtained with a $0.5 \mathrm{ml}$. portion of the mixture of $8 \mathrm{~g}$. chromium trioxide, $5 \mathrm{ml}$. water, and $15 \mathrm{ml}$. concentrated nitric acid as oxidant. The optimum digestion temperature was about $65^{\circ} \mathrm{C}$., and digestion at this temperature had to be continued for at least 4 hours (Fig. 2).

Optimum Conditions for Fujiwara Reaction The samples developed the maximum colour with $\mathrm{KOH}$ solution between 7.0 and $8.6 \mathrm{~N}$. Hence $7.8 \mathrm{~N} \mathrm{KOH}$ was chosen for routine use. Figure 3 shows that at least 40 minutes were required for colour development in the Fujiwara reaction. The intensity of colour did not decline for at least one hour after it reached its plateau, so a reaction time of 50 minutes was thought to be sufficient.

Comparative Study on Seto and Schultze's (1956) Method and the Present Modification Both Seto and Schultze's (1956) method and the present modification gave satisfactory recoveries of TCA, added to the urine from various species of animals (Table I). In contrast, the recoveries of TCE added to urine were rather poor by Seto and Schultze's method. Satisfactory recoveries $(>95 \%)$ were obtained with the present modification in which more drastic oxidative conditions were employed.

\section{Application of the Modified Method to the}

\section{TABLE I}

Recovery of Trichloroethanol and Trichloroacetic Acid Added to Human Urine and the Urine of Several Species of ANimals; Comparison Between Seto and Schultze's (I956) Method and the Present Modification

\begin{tabular}{|c|c|c|c|c|c|}
\hline & \multirow{2}{*}{$\begin{array}{c}\text { Rat } \\
(\text { female })\end{array}$} & \multirow{2}{*}{$\begin{array}{l}\text { Rabbit } \\
\text { (male) }\end{array}$} & \multirow{2}{*}{$\begin{array}{l}\text { Guinea-pig } \\
(\text { female })\end{array}$} & \multicolumn{2}{|c|}{ Human } \\
\hline & & & & (male) & (female) \\
\hline Determinations & 9 & 5 & 5 & 7 & 7 \\
\hline $\begin{array}{l}\text { TCA } \\
\text { Seto and Schultze's method (I956). } \\
\text { Modification }\end{array}$ & $\begin{array}{l}96 \cdot 5 \pm 3 \cdot 8 \\
94.9 \pm 3 \cdot 1\end{array}$ & $\begin{array}{l}98 \cdot 3 \pm \mathrm{I} \cdot 8 \\
98 \cdot 7 \pm \mathrm{I} \cdot 0\end{array}$ & $\begin{array}{l}98.4 \pm 0.8 \\
96.3 \pm 3.3\end{array}$ & $\begin{array}{r}100 \cdot 1 \pm 3 \cdot 0 \\
96 \cdot 8 \pm 1 \cdot 0\end{array}$ & $\begin{aligned} 100.6 & \pm 3.5 \\
97.6 & \pm 2.4\end{aligned}$ \\
\hline $\begin{array}{l}\text { TCE } \\
\text { Seto and Schultze's method (1956). } \\
\text { Modification }\end{array}$ & $\begin{array}{l}16.2 \pm 12 \cdot 3 \\
97.4 \pm 3.0\end{array}$ & $\begin{array}{l}79 \cdot 2 \pm 8 \cdot 9 \\
95 \cdot 9 \pm 2 \cdot 5\end{array}$ & $\begin{array}{l}8 \mathrm{I} \cdot 3 \pm 13 \cdot 4 \\
98 \cdot 2 \pm 1 \cdot 6\end{array}$ & $\begin{array}{l}73 \cdot 8 \pm 3 \cdot 1 \\
98 \cdot 5 \pm 2 \cdot 1\end{array}$ & $\begin{array}{l}75 \cdot 3 \pm 6 \cdot 0 \\
98 \cdot 1 \pm 2 \cdot 0\end{array}$ \\
\hline
\end{tabular}

For rats and guinea-pigs the urine from 7 rats or 5 guinea-pigs was pooled for each determination. Individual urine samples were used for humans and rabbits. An aliquot of either TCA $(2 \mu \mathrm{moles} / \mathrm{ml}$.) or TCE ( $2 \mu \mathrm{moles} / \mathrm{ml}$.) solution was mixed with an equal volume of the urine (or water, in the case of control), and the mixture was analysed by Seto and Schultze's (1956) method and by the modified method. Means and standard deviations of percentages are given, where percentages were calculated by $100 \mathrm{E}_{\mathrm{u}} / \mathrm{E}_{\mathrm{w}}$ where $\mathrm{E}_{\mathrm{u}}$ was the extinction measured when the standard solution was mixed with urine and $\mathrm{E}_{\mathrm{w}}$ was that when mixed with water. 


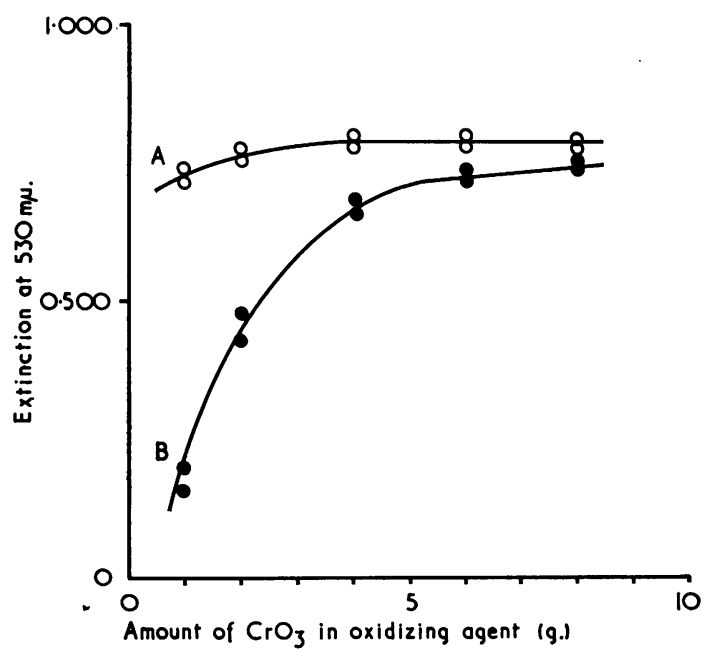

FIG. I. Effect of chromium trioxide concentration on oxidation of trichloroethanol.

Extinction was measured after mixing $0.25 \mathrm{ml}$. of $2 \mu$ moles $\mathrm{TCE} / \mathrm{ml}$. and $0.25 \mathrm{ml}$. water or rat urine treated as described under Methods, except that the amount of chromium trioxide added in the oxidizing mixture was varied from I to $8 \mathrm{~g}$. (A) TCE and water; (B) TCE and rat urine.

Urine Samples of Trichloroethylene-exposed Workers The modified method was used to determine the TCE and TCA levels in the urine of those with no known exposure to trichloroethylene and of those exposed to trichloroethylene in their

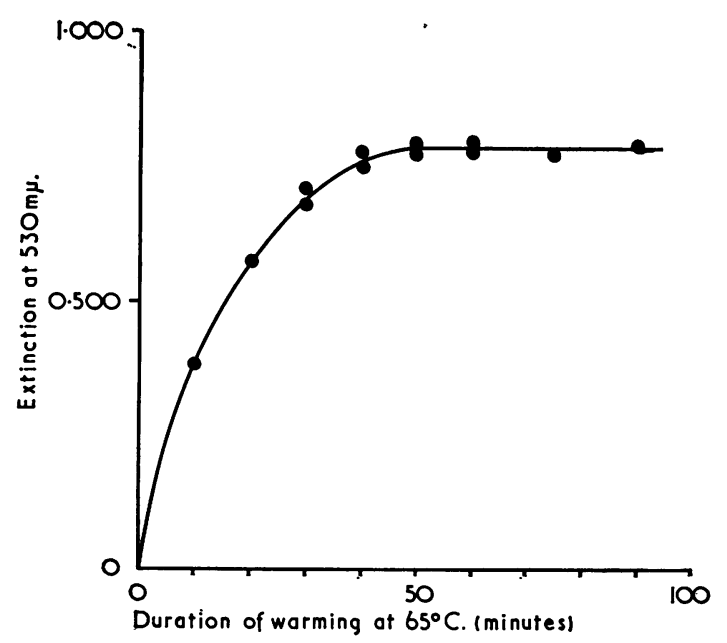

Fig. 3. Effect of time at $65^{\circ} \mathrm{C}$. on the development of colour in the Fujiwara reaction. daily work. The results are summarized in Table II.

In the former group, 30 men and 34 women, the amounts of the two compounds were very small and rarely exceeded $2 \mathrm{mg}$./litre. In the latter group there were 14 men exposed 8 hours daily to 120 to 250 p.p.m. of trichloroethylene and II women exposed 8 hours daily to 20 to 80 p.p.m. The concentrations of the two compounds in the urines of trichloroethylene-exposed groups were much higher than in the urines of the non-exposed group.

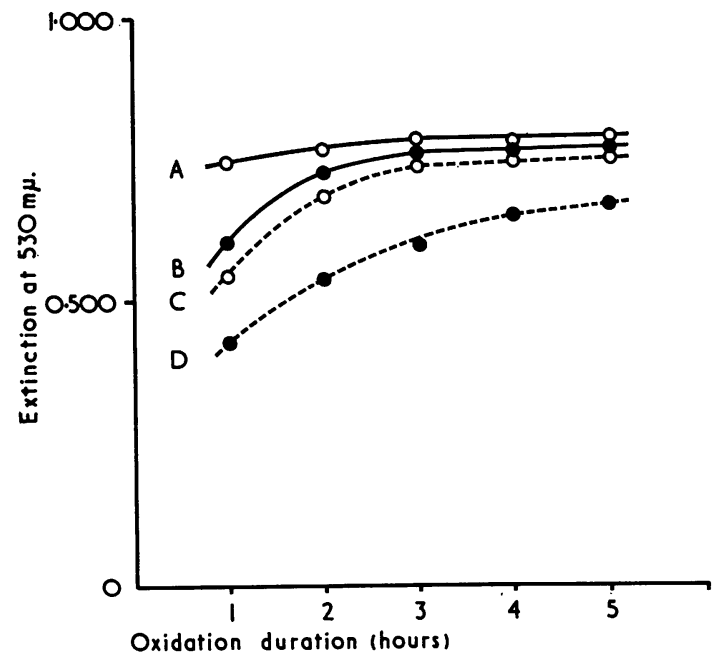

FIG. 2. Effect of nitric acid concentration and duration of digestion on oxidation of trichloroethanol.

As for Fig. I. except that the components of the oxidizing mixture were varied as below, and the duration of digestion at $65^{\circ} \mathrm{C}$. was varied from one to five hours.

\begin{tabular}{|c|c|c|c|c|}
\hline \multirow{2}{*}{ Symbols } & \multirow{2}{*}{ Samples } & \multicolumn{3}{|c|}{ Components of the Oxidant } \\
\hline & & $\begin{array}{l}\mathrm{CrO}_{8} \\
\text { (g.) }\end{array}$ & $\begin{array}{c}\mathrm{H}_{2} \mathrm{O} \\
(\mathrm{ml} .)\end{array}$ & $\begin{array}{c}\left.H N O_{8}\right) \\
H\end{array}$ \\
\hline $\begin{array}{l}\text { A } \\
\text { B } \\
\text { C } \\
\text { D }\end{array}$ & $\begin{array}{l}\text { TCE and water } \\
\text { TCE and water } \\
\text { TCE and rat urine } \\
\text { TCE and rat urine }\end{array}$ & $\begin{array}{l}8 \\
8 \\
8 \\
8\end{array}$ & $\begin{array}{r}5 \\
10 \\
5 \\
10\end{array}$ & $\begin{array}{l}15 \\
10 \\
15 \\
10\end{array}$ \\
\hline
\end{tabular}

In the exposed groups, the concentrations of the two compounds were increased approximately in proportion to the trichloroethylene concentration in air. The average ratio: TCE/TCA was higher in the group with the higher exposure (men).

To elucidate whether the ratio: TCE/TCA varied with the trichloroethylene concentration in the air, female rats were exposed to trichloroethylene at various concentrations for 8 hours and urine 
TABLE II

Urinary Excretion of Trichloroacetic ACID aNd Trichloroethanol (Mg./Litre) from Normal SUBJECTS AND TRICHLOROETHYLENE-EXPOSED WORKERS

\begin{tabular}{|c|c|c|c|c|c|c|}
\hline \multicolumn{3}{|c|}{ Group } & Metabolites & Male & Female & \multirow{2}{*}{$\frac{\text { Exposure Level }}{\text { No known exposure }}$} \\
\hline Not exposed ${ }^{1}$ & & $\cdots$ & $\begin{array}{l}\text { TCA } \\
\text { TCE }\end{array}$ & $\begin{array}{c}0.13 \pm 0.22 \\
(30) \\
0.03 \pm 0.05\end{array}$ & $\begin{array}{l}0.08 \pm 0.19 \\
0.03 \pm 0.04\end{array}$ & \\
\hline \multirow{2}{*}{\multicolumn{3}{|c|}{ Trichloroethylene-exposed workers }} & $\begin{array}{r}\text { TCA } \\
\text { TCE } \\
\text { TCE : TCA }\end{array}$ & $\begin{array}{l}79 \cdot 3 \pm 47 \cdot 9 \text { (I4) } \\
\text { I32.7 } \pm 95 \cdot 9 \\
I \cdot 7: I\end{array}$ & & $\begin{array}{l}\text { I } 20 \text { to } 250 \text { p.p.m. daily, } \\
8 \text { hours a day, } \\
\text { six days a week }\end{array}$ \\
\hline & & & $\begin{array}{r}\text { TCA } \\
\text { TCE } \\
\text { TCE : TCA }\end{array}$ & & $\begin{array}{l}45.8 \pm 28.0 \\
40.7 \pm 22 \cdot 1 \\
0.9: 1\end{array}$ & $\begin{array}{l}20 \text { to } 80 \text { p.p.m. daily, } \\
8 \text { hours a day, } \\
\text { six days a week }\end{array}$ \\
\hline
\end{tabular}

${ }^{1}$ University students, $18-23$ years old. $\quad{ }^{2}$ Determined with Kitagawa detecting tubes.

Values are means \pm S.Ds. Numbers of subjects are in parentheses.

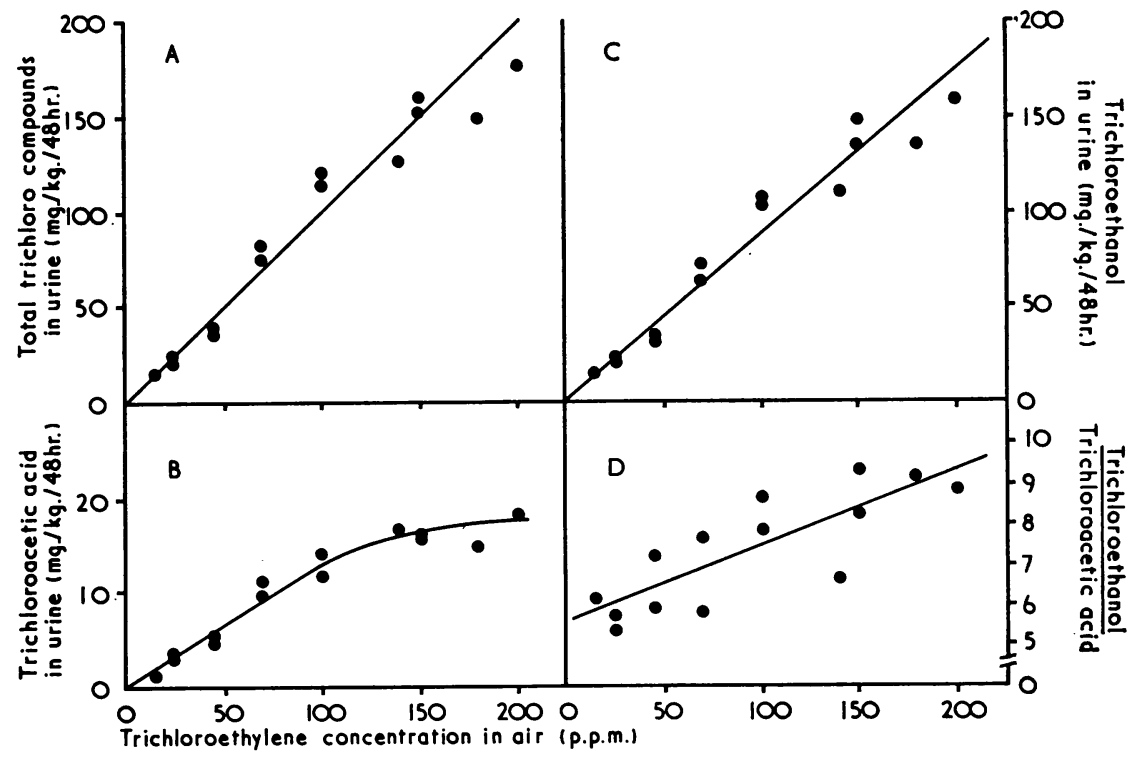

FIG. 4. Relation between environmental trichloroethylene concentration and urinary metabolites: (A) total trichlorocompounds; (B) trichloroacetic acid; (C) trichloroethanol; (D) ratio of trichloroethanol to trichloroacetic acid.

Groups of female Wistar rats, weighing about 50 g., and six animals per group, were exposed to trichloroethylene at various concentrations for 8 hours. Urine from each group was collected for 48 hours from the beginning of the exposure. Each point in the figure represents the amount of metabolite in each urine sample thus obtained. Lines in Fig. 4A, C, and D are calculated regression lines. The curve in Fig. 4B was drawn by eye. 
samples were collected for 48 hours. The amounts of metabolites excreted afterwards were less than $5 \%$ of those excreted within the initial 48 hours. The total trichloro-compounds in urine increased in proportion to the trichloroethylene concentration in air (Fig. 4A). The TCA in urine was, however, only proportional to the trichloroethylene concentration up to 100 p.p.m., and was no longer proportional when the concentration was elevated further (Fig. 4B). TCE (i.e., total trichlorocompounds minus TCA) also increased in proportion to the trichloroethylene exposure because the amount of TCA was much smaller than that of total trichloro-compounds (Fig. $4 \mathrm{C}$ ). The ratio: TCE/TCA increased from below 6 to over 9 when trichloroethylene concentrations were varied from I5 p.p.m. to 200 p.p.m. (Fig. 4D).

\section{Discussion}

The determination of TCE by Seto and Schultze's (1956) method was employed in our study at first but this gave poor recoveries of TCE added to the urine of human subjects and various species of animals (Table I). Rat urine gave recoveries of TCE too low for reasonable estimation by this method. The critical part of this procedure seemed to be the oxidation of trichloro-compounds to TCA. It was suspected that the oxidizing conditions described by Seto and Schultze (1956) for bovine urine were not drastic enough for the urine of other animals. Therefore, a more powerful oxidizing reagent and a higher oxidation temperature were tested. When aqueous solutions of TCE were analysed by Seto and Schultze's method and the present modification, no significant differences were observed; but on urine samples the present modification gave better recoveries than Seto and Schultze's method (Table I). Seto and Schultze probably employed mild conditions from a fear that further destruction of trichloro-compounds and TCA might occur; but under the more drastic oxidizing conditions employed here no indication of such a break-down was observed.

The quantities of the reagents were also varied from those used by Seto and Schultze. In order to make it simple to compare oxidative and nonoxidative procedures identical volumes of reagents were used in both. The TCA estimation only differed in not undergoing oxidation because the sample was mixed with $\mathrm{KOH}$ before the addition of oxidizing agent. The same recoveries of TCA added to water were then obtained whether oxidation was carried out or not. When tested on the urine of various species TCA recoveries were marginally lower than those obtained by Seto and
Schultze's method (Table I). It was also convenient to use a water bath at the same temperature for both oxidation and the Fujiwara reaction.

The oxidation method given by Vlachová (1957) was applied to TCE determination in urine, in which $2 \mathrm{~g}$. potassium bichromate in $70 \mathrm{ml}$. concentrated sulphuric acid and $30 \mathrm{ml}$. water are used, and oxidation is carried out at $70^{\circ} \mathrm{C}$. for 5 minutes. Recoveries of TCE and TCA were similar but very low, possibly due to the heavy precipitation of salt observed in this method rather than to the incomplete oxidation of TCE.

The metabolism of trichloroethylene is as in Fig. 5 (Butler, 1949; Leibman, 1965; Byington and

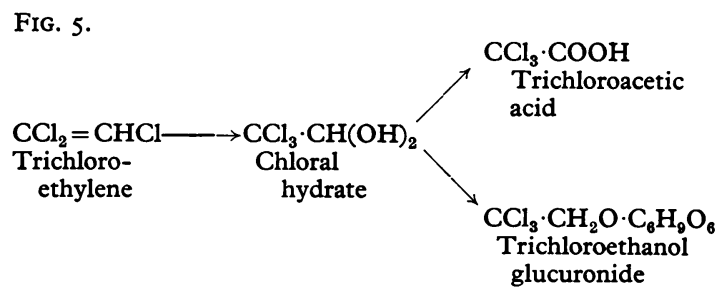

Leibman, 1965; Cooper and Friedman, 1958; Friedman and Cooper, 1960). Of particular importance and interest is the fact that TCA and TCE are derived from chloral hydrate independently of each other, i.e., conversion of TCE to TCA, or vice versa, does not occur. Soucěk and Vlachová (I960) reported that in their human experiments an average of $73 \%$ of the trichloroethylene calculated to be retained by the body was excreted into the urine as TCE $(50 \%)$, TCA (19\%), and monochloroacetic acid $(4 \%)$. For industrial hygiene purposes, therefore, determination of TCE as well as TCA in urine is considered to give the most representative picture of trichloroethylene exposure and absorption. When the modified method was applied to the urine of two groups of factory workers, the results varied from subject to subject, probably reflecting variations in exposure and also probably variations in excretion rate, as only single urine samples were taken. However, the average levels of TCE and TCA in each group reflected the exposure level. The ratio: TCE/TCA in the urine of the factory workers reported here ranged from 0.73 to 4.20 (average $I \cdot 69$ ) in one group and 0.58 to 1.43 (average 0.9 ) in the other group and agree well with those reported by others, e.g., 2 to 7 by Teisinger and his colleagues or 0.5 to 5 by Bardodej and Krivucová, both as quoted by Soucěk and Vlachová (1960). This ratio was higher in the group exposed to higher concentrations of trichloro- 
ethylene than in the group exposed to lower concentrations. Further experiments with rats clearly proved that the ratio increased as the environmental concentrations of trichloroethylene were increased. Conversely, TCA constituted a smaller fraction of the metabolites when trichloroethylene concentrations were high. It is therefore of practical importance to determine the total trichloro-compounds in urine rather than TCA alone as an index of exposure of factory workers exposed to trichloroethylene.

A part of this paper was presented at the 25th Annual Conference of the Japanese Public Health Association in Sendai, Japan, October 18-20, 1967.

This work was in part supported by research grants from the Fujiwara Memorial Fund.

\section{REFERENCES}

Butler, T. C. (1949). Metabolic transformations of trichloroethylene. f. Pharmacol. exp. Ther., 97, 84-92.

Byington, K. H., and Leibman, K. C. (1965). Metabolism of trichloroethylene in liver microsomes. II. Identifica- tion of the reaction product as chloral hydrate. Molecular Pharmacol., I, 247-254.

Cooper, J. R., and Friedman, P. J. (1958). The enzymic oxidation of chloral hydrate to trichloroacetic acid. Biochem. Pharmacol., I, 76-82.

Defalque, R. J. (I96I). Pharmacology and toxicology of trichloroethylene. A critical review of the world literature. Clin. Pharmacol. Ther., 2, 665-688.

Friedman, P. J., and Cooper, J. R. (1960). The role of alcohol dehydrogenase in the metabolism of chloral hydrate. F. Pharmacol. exp. Ther., 129, 373-376.

Leibman, K. C. (1965). Metabolism of trichloroethylene in liver microsomes. I. Characteristics of the reaction. Molecular Pharmacol., 1, 239-246.

The Merck Index of Chemicals and Drugs (1952). 6th ed., Merck and Co., Inc., Rahway, New Jersey, U.S.A.

The Pharmacopeia of the U.S.A. (1960). 16th revision.

Seto, T. A., and Schultze, M. O. (1956). Determination of trichloroethylene, trichloroacetic acid, and trichloroethanol in urine. Analyt. Chem., 28, 1625-1629.

Smith, G. F. (1966). Trichloroethylene: a review. Brit. $\mathcal{F}$. industr. Med., 23, 249-262.

Soucěk, B., and Vlachová, D. (1960). Excretion of trichloroethylene metabolites in human urine. Ibid., 17, 60-64.

Vlachová, D. (1957). An easy method for the determination of trichloroethanol in the urine after exposure of trichloroethylene. F. Hyg. Epidem. (Praha), 1, 225-229. 